\title{
Leadership and early strategic response to the SARS- CoV-2 pandemic at a COVID-19 designated hospital in South Africa
}

\begin{abstract}
A Parker, ${ }^{1,2}$ MB ChB, FCP (SA), MMed (Int Med), Cert ID (SA) Phys; S Karamchand, ${ }^{2}$ MB ChB, BPharm, MSc (Med) Clin Pharm; N Schrueder, ${ }^{2}$ MB ChB, FCP (SA); S Lahri, ${ }^{3} \mathrm{MB}$ ChB, FCEM (SA); H Rabie, ${ }^{4} \mathrm{MB}$ ChB, MMed, FC Paed (SA), MSc (ID), PhD; M Aucamp, ${ }^{5}$ BSocSc (Nursing), PG Dip Infection Control, MPhil, HPE; R Abrahams, ${ }^{2}$ BSc, BSc (Med Sci) Hons, MB ChB, MMed (Micro Path), DTM\&H, PG Dip IPC; P Ciapparelli, ${ }^{6} \mathrm{MB}$ ChB, MBA; D S Erasmus, ${ }^{6} \mathrm{MB} \mathrm{ChB}, \mathrm{MSc}, \mathrm{MBA}$; M F Cotton, ${ }^{3,7}$ MB ChB, MMed (Paed), FC Paed (SA), PhD, DCH (SA), DTM\&H; U Lalla, ${ }^{8}$ MB ChB, FCP (SA), MMed (Int Med), Cert Crit Care (SA) Phys; R Leisegang, ${ }^{7}$ BSc (Chem Eng), MB ChB, PhD (Clin Pharm), Core Epi Cert (UNC); J Meintjes, ${ }^{5} \mathrm{MB}$ ChB, DOM, FCPHM (SA) Occ Med, MMed (Occ Med); R Mistry, ${ }^{6,8} \mathrm{MB}$ ChB, DCH (SA), Dip Allerg (SA), Dip HIV Man (SA), MBA; M R Moosa, ${ }^{9} \mathrm{MB}$ ChB, FCP (SA), MD, FRCP; A Mowlana, ${ }^{2} \mathrm{MB}$ ChB, FCP (SA), MMed (Int Med); C F N Koegelenberg, ${ }^{10} \mathrm{MB}$ ChB, FCP (SA), MMed (Int Med), FRCP, Cert Pulm (SA), PhD; H Prozesky, ${ }^{2}$ MB ChB, MMed (Int Med); W Smith, ${ }^{11,12}$ MB ChB, EMDM, FCEM (SA); M van Schalkwyk, ${ }^{1}$ MD, GH\&TM, Dip HIV Man (SA); J J Taljaard, ${ }^{1}$ MB ChB, MMed (Int Med), DTM\&H
\end{abstract}

\footnotetext{
${ }^{1}$ Division of Infectious Diseases, Department of Medicine, Faculty of Medicine and Health Sciences, Stellenbosch University and Tygerberg Hospital, Cape Town, South Africa

${ }^{2}$ Division of General Internal Medicine, Department of Medicine, Faculty of Medicine and Health Sciences, Stellenbosch University and Tygerberg Hospital, Cape Town, South Africa

${ }^{3}$ Division of Emergency Medicine, Department of Medicine, Faculty of Medicine and Health Sciences, Stellenbosch University and Tygerberg Hospital, Cape Town, South Africa

${ }^{4}$ Division of Paediatric Infectious Diseases, Department of Paediatrics and Child Health, Faculty of Medicine and Health Sciences, Stellenbosch University and Tygerberg Hospital, Cape Town, South Africa

${ }^{5}$ Unit for Infection Prevention and Control, Tygerberg Hospital, Cape Town, South Africa

${ }^{6}$ Hospital Management, Tygerberg Hospital and Faculty of Medicine and Health Sciences, Stellenbosch University, Cape Town, South Africa

${ }^{7}$ Family Centre for Research with Ubuntu (FAMCRU), Stellenbosch University, Cape Town, South Africa

${ }^{8}$ Division of Critical Care, Department of Medicine, Faculty of Medicine and Health Sciences, Stellenbosch University and Tygerberg Hospital, Cape Town, South Africa

${ }^{9}$ Department of Medicine, Faculty of Medicine and Health Sciences, Stellenbosch University and Tygerberg Hospital, Cape Town, South Africa ${ }^{10}$ Division of Pulmonology, Department of Medicine, Faculty of Medicine and Health Sciences, Stellenbosch University and Tygerberg Hospital, Cape Town, South Africa

${ }^{11}$ Division of Emergency Medicine, Department of Surgery, Faculty of Health Sciences, University of Cape Town

${ }^{12}$ Disaster Medicine Unit, Emergency Medical Services, Cape Town, South Africa
}

Corresponding author: A Parker (aparker@sun.ac.za)

While many countries are preparing to face the COVID-19 pandemic, the reported cases in Africa remain low. With a high burden of both communicable and non-communicable disease and a resource-constrained public healthcare system, sub-Saharan Africa is preparing for the coming crisis as best it can. We describe our early response as a designated COVID-19 provincial hospital in Cape Town, South Africa (SA). While the first cases reported were related to international travel, at the time of writing there was evidence of early community spread. The SA government announced a countrywide lockdown from midnight 26 March 2020 to midnight 30 April 2020 to stem the pandemic and save lives. However, many questions remain on how the COVID-19 threat will unfold in SA, given the significant informal sector overcrowding and poverty in our communities. There is no doubt that leadership and teamwork at all levels is critical in influencing outcomes.

S Afr Med J. Published online 22 April 2020. https://doi.org/10.7196/SAMJ.2020.v110i6.14809

African countries are preparing to face the outbreak of COVID19, which the World Health Organization declared a Global Public Health Emergency of International Concern on 31 January $2020^{[1]}$ and a pandemic 40 days later. ${ }^{[2]}$ COVID-19 is caused by the severe acute respiratory syndrome coronavirus-2 (SARS-CoV-2). The virus, emerging in early December 2019 in Wuhan, Hubei Province, China, ${ }^{[3]}$ has since spread explosively throughout the world. Most of Europe and the USA has been severely affected in recent weeks despite their relatively high income per capita and robust public healthcare systems. In contrast, African countries are poorly resourced, have a sizeable vulnerable population, and in recent years noticeably demonstrated vulnerability to epidemics. ${ }^{[4]}$

Many South Africans of all ages have significant risk factors for severe COVID-19 outcomes. The pre-existing colliding epidemics of HIV infection and tuberculosis (TB), as well as the high prevalence of non-communicable diseases such as hypertension, diabetes and cardiovascular disease, place a large segment of the population at high risk. ${ }^{[5]}$ 
While South Africa (SA) is classified as an upper-middle-income country, it has one of the highest inequality indexes globally, extending into the healthcare sector. ${ }^{[6]}$ Public sector facilities remain in a state of crisis, while resources available in the private sector, offering worldclass care, are accessible to only $16 \%$ of the population. ${ }^{[5]}$ The SARS$\mathrm{CoV}-2$ pandemic demands a unified response across society and emphasises the need for a universal healthcare approach. ${ }^{[7]}$

Cape Town is at high risk for COVID-19, given the frequency of air travel and its popularity as a travel destination. Tygerberg Hospital (TBH), the largest public sector tertiary referral hospital in the Cape Town Metropole in Western Cape Province, is located close to the international airport and serves over 3.4 million people, mostly vulnerable populations from densely populated low-income communities and rural areas. We report on our early experiences as a designated provincial COVID-19 centre preparing for the imminent community outbreak of COVID-19.

Ethics approval for this article was obtained from the Health Research Ethics Committee of Stellenbosch University (ref. no. N20/04/006_COVID-19).

\section{Phase 1 response (imported cases)}

The TBH adult and paediatric infectious diseases (ID) teams in collaboration with the Unit for Infection Prevention and Control (UIPC) and the Western Cape Centre for Disease Control (CDC) and Emergency Medicine Services (EMS), spearheaded a rapid and early response preceding any confirmed COVID-19 cases in the country. The aim of the first response was to prepare for potential COVID-19 cases arriving via port health. A separate entrance to the hospital was identified and safe transfer of suspected cases to the designated isolation ward was established by deploying security services, dedicating elevators and using mobile technology to keep staff up to date with progress of a transfer. The first designated management area at TBH was the 32-bed respiratory isolation ward for TB patients. Existing patients were either discharged to community care, or referral was fast-tracked to designated TB hospitals. The ward has eight single isolation rooms and four 6-bed rooms to cohort confirmed cases. The initial workload was shared among the small group of ID clinicians and UIPC practitioners. On 6 February 2020, a 'dry run' with a dummy patient was done to test the processes on the planned route from airport to isolation room.

Initially, all potential COVID-19 'persons under investigation' (PUI) required approval for testing from the National Institute of Communicable Diseases (NICD) in Johannesburg, the national reference laboratory responsible for managing epidemics. The samples were dispatched to the NICD central laboratory with results being available after 48 - 96 hours. Processing of test samples has since been decentralised to the on-site National Health Laboratory Service (NHLS) virology laboratory, reducing sample turnaround time to 12 - 48 hours.

\section{The first cases}

From 28 January 2020, the initial cohort of potential COVID-19 cases were mostly previously healthy travellers from China who self-presented to TBH for screening. The first 4 patients admitted tested negative for SARS-CoV-2 but positive for influenza B $(n=1)$, influenza A $(n=2)$ and parainfluenza $(n=1)$, a reminder that viral infections traditionally less common during our summer months are often imported by travellers from the northern hemisphere.

The first confirmed COVID-19 case in SA was announced on 5 March 2020, a traveller returning to Johannesburg from Italy, while the first case in the Western Cape was announced on 11 March 2020, a traveller returning from Germany, Austria, Switzerland and Turkey.
Soon afterwards, referrals from primary and secondary public healthcare centres and independent private practitioners escalated. From 28 January to 15 March we had screened 93 patients.

During this time the ID team and UIPC staff were inundated with calls for advice from the public, including commercial trade and shipping agents, and schools. ID and UIPC also served as a resource for both community and healthcare facilities. The team drafted standard operating procedures and created posters with instructions for visual display. Educational material was shared widely within the institution.

\section{Phase 2 response (limited local transmission)}

During phase 2, the General Internal Medicine team redirected human resources, senior and junior, to support the ID team. By midMarch, a dedicated COVID-19 testing unit was established outside the hospital entrance situated closest to the hospital's main gate. Clear signage directed the public towards this entrance and away from other entrances, ensuring that patient flow was in alignment with infection prevention and control (IPC) best practices. The screening area included a mobile unit and a tent provided by the EMS Disaster Medicine Unit, clinical cubicles, two negative-pressure sampling rooms (providing 60 air changes per hour, to allow for rapid clearance of potential airborne pathogens and therefore rapid reuse of the rooms) and an associated repurposed operating theatre equipped to manage patients presenting in respiratory distress. The unit was staffed with a multidisciplinary team of medical staff and registered nurses from the divisions of ID, UIPC, Emergency Medicine (EM), Paediatrics and Internal Medicine. A 'war room' was commissioned for senior leaders to meet regularly and plan a co-ordinated 'whole of hospital' response.

\section{Patient and staff information}

Educational material, including pamphlets and videos, was created by UIPC and paediatric and adult ID and circulated widely to staff in the hospital and to other healthcare facilities provincially and nationally via various electronic and social media platforms. It included videos on how to perform a nasopharyngeal swab and how to 'don' and 'doff' personal protective equipment (PPE), and a video on self-isolation. The educational video on safe self-isolation was sent directly to patients via WhatsApp. There was extensive hands-on training and re-training, during which staff fears were addressed. Staff fears were extensive, but continuous support from IPC practitioners, role modelling from senior clinicians, and increasing hands-on experience empowered most with confidence and pride in what they were doing.

\section{COVID-19 public hotline}

The National Department of Health established a COVID-19 public health hotline, which was soon put under enormous pressure as call volumes exceeded capacity. A provincial 24-hour hotline to assist the public was established within 2 days, staffed by EM practitioners and student volunteers. Clinical support for the hotline was from EM and ID consultants and registrars.

\section{Personal protective equipment}

Conflicting early guidelines and recommendations created confusion around appropriate PPE use. There was also a conflict between the guidelines and media images of healthcare staff wearing full body coverage in Wuhan. Crucial to the whole hospital response has been a concerted effort to standardise PPE use. A policy aimed at protecting this valuable resource was developed, ensuring appropriate use, minimising wastage and preventing stock shrinkage. This included 
establishing a dedicated team to monitor use and follow up when use exceeded the predicted norms.

\section{Staff health}

The Occupational Health unit developed protocols for individual risk assessment and classification of staff members at risk to protect those considered at risk for severe disease. A process was implemented to provide a personalised protection plan, including the provision of special leave for very vulnerable individuals. Likewise, a system was implemented to test staff members presenting with respiratory symptoms that would allow for early return to work and prevent staff shortages.

\section{State of National Disaster}

On 15 March 2020, President Cyril Ramaphosa declared a State of National Disaster and advised all international travellers to be screened for testing. This announcement resulted in a 25 -fold increase in cases screened. The test results were communicated to the patients by the outpatient ID team, subsequently supported by a group of volunteers as the test numbers rapidly escalated. Groups of staff from other disciplines in the hospital, as well as from surrounding community health centres, are being trained in testing and IPC protocols through this unit. Simple measures such as separating and masking those with coughs and getting patients to move with their chairs to different evaluation stages saved valuable resources. The TBH intensive care unit (ICU) capacity was reviewed. The medical ICU, consisting of 7 existing ICU beds and 8 high-care beds, was identified to manage critically ill COVID-19 patients and PUI. An infrastructural assessment identified 42 potential ICU bed spaces. Of these, 28 'functional' ICU beds equipped with ventilators, monitors and other necessary equipment were commissioned prior to the first COVID-19 admission. The lack of supply of ventilators (internationally) limited this response to 28 beds. However, the number of ICU beds is still woefully short of the estimated need.

Phase 3 response (community spread) In anticipation of a community outbreak, the hospital management co-ordinated a multidivision and multidepartmental effort. All nonessential outpatient clinics were rapidly scaled down or closed and elective theatre slates were cancelled, along with timeous inpatient discharges. Within 3 weeks, the following were established: a dedicated 24-hour screening and testing unit able to triage and manage severely ill patients presenting de novo, fully staffed COVID-19-dedicated wards with isolation capabilities and daily operational meetings keeping track of PPE, and pharmacy and other equipment stock. The immediately available COVID-19 bed capacity was expanded to 172 beds with plans to escalate in a phased response as needed. Further expansion to the ICU and high-care facilities included the conversion of a 31-bed ward adjacent to the ICU into a high-care facility with dedicated intubation facilities, and converting an unused kitchen to shower facilities for staff. Critically ill 'non-COVID-19' patients were diverted to other ICU facilities in the hospital (including existing general surgery, cardiothoracic, and neurosurgical ICU beds).

\section{Staffing and volunteer recruitment}

Hospital medical staff were divided into COVID-19 and nonCOVID-19 teams. The non-COVID-19 teams provided ongoing care to patients in need of essential medical care, as well as intensive telephonic outreach and support to secondary and district hospitals. Volunteers have been recruited from surrounding private institutions and universities for duty when the caseload increases. The rapid execution of these measures in this overburdened and understaffed public hospital represents unprecedented co-ordination of services and dedicated interdisciplinary leadership.

\section{Additional infrastructure}

An on-site light infrastructure facility for triage, testing and treating was commissioned by the hospital to facilitate respiratory triage outside the hospital, and will allow for additional bed space if the need arises.

\section{The lockdown}

Given the potential consequences of community spread of COVID19 in SA, the SA government announced a countrywide lockdown from midnight 26 March 2020 to midnight 16 April 2020, now extended for 2 more weeks, in an effort to stem the pandemic in SA. On 6 April 2020, extended screening and testing to densely occupied communities was rolled out. This proactive response aims to flatten the epidemic curve and it is hoped will reduce the burden on healthcare facilities like TBH.

\section{Conclusions}

We are acutely aware that our measures may be insufficient in the event of a widespread community outbreak. Predicting how the pandemic will unfold in SA is difficult. Many South Africans come from marginalised communities and live either in densely populated informal housing or shared accommodation, often with the elderly and the young in one room. At this stage, it is unknown whether HIV or TB-related lung disease will result in more severe illness. We are also concerned about the potential 'collateral damage' of cancelled elective surgery and outpatient visits on the overall morbidity and mortality of an already constrained public healthcare system.

Strategic leadership is fundamental to any emergency response. The critical lesson is to act swiftly and respond proportionately. Key to our response are practical leaders who are adaptable and can communicate while the crisis is unfolding, reflect on what they have learned daily, and implement changes immediately. An essential element in our whole response to COVID-19 is, and will continue to be, multidisciplinary teamwork.

Acknowledgements. The authors thank all staff of TBH, including clinical, administrative, security, cleaning, laundry, porters, nursing and management teams. We thank staff from EMS, Disaster Medicine, the NICD, the NHLS and the provincial CDC. We thank all volunteers and healthcare workers involved in the COVID-19 response.

Author contributions. AP, SL, NS and JJT conceptualised the article. All authors contributed equally to and approved the final manuscript.

Funding. None.

Conflicts of interest. None.

1. World Health Organization. 2019-nCoV is an emergency of international concern. http://www.euro. who.int/en/health-topics/health-emergencies/coronavirus-covid-19/news/news/2020/01/2019-ncovoutbreak-is-an-emergency-of-international-concern (accessed 6 April 2020).

2. World Health Organization. WHO announces COVID-19 a pandemic. http://www.euro.who.int/en health-topics/health-emergencies/coronavirus-covid-19/news/news/2020/3/who-announces-covid19-outbreak-a-pandemic (accessed 6 April 2020).

3. Huang C, Wang Y, Li X, et al. Clinical features of patients infected with 2019 novel coronavirus in Wuhan, China. Lancet 2020;395(10223):497-506. https://doi.org/10.1016/S0140-6736(20)30183-5

4. Talisuna AO, Okiro EA, Yahaya AA, et al. Spatial and temporal distribution of infectious disease epidemics, disasters and other potential public health emergencies in the World Health Organization Africa Region, 2016 - 2018. Glob Health 2020;16(1):9. https://doi.org/10.1186/s12992-019-0540-4

5ayosi BM, Benatar SR. Health and health care in South Africa - 20 years after Mandela. N Engl J Med 2014;371(14):1344-1353. https://doi.org/10.1056/NEJMsr1405012

6. World Bank. The World Bank in South Africa. 2019. https://www.worldbank.org/en/country/ World Bank. The World Bank in South

southafrica/overview (accessed 6 April 2020).
Gates B. Responding to Covid-19 - a once-in-a-century pandemic? N Engl J Med 2020 (epub 28 February 2020). https://doi.org/10.1056/NEJMp2003762 